\title{
Taking a wider look at multitasking through a triple-task
}

\author{
Maximilian Stefani ${ }^{1}$, Marian Sauter ${ }^{1}$, Franziska Eichert ${ }^{1}$, and Wolfgang Mack ${ }^{1}$ \\ ${ }^{1}$ General Psychology, Institute for Psychology, Universität der Bundeswehr München \\ maximilian.stefani@unibw.de
}

PREPRINT

\begin{abstract}
In the past, multitasking research was dominated by different dual-task paradigms. Although dual tasks allow for large variations - simultaneous processing, sequential processing, or task-switching - this variability is still far from complex everyday multitasking affording situations. This study aimed to examine the effects of three two-choice simultaneous tasks and to compare them with historic dual-tasks and discuss fitting models. The triple-task consisted of two visual tasks and one auditory task. Crucially, participants had to switch the stimulus-response (S-R) pairing of both visual tasks in half of the session from standard $S$ - $R$ pairings (e.g. location task and hand response) to non-standard $S-R$ pairings (e.g. color task and feet response) or vice-versa. Our results showed that response times in the triple-task were up to two times higher than in dual-tasks in comparable studies. Additionally, both visual tasks were responded to similarly fast although they consisted of standard and non-standard feature pairings. It also seemed to be easier for participants to switch the $S-R$ pairings concerning their 'hand'-response from non-standard S-R pairings to standard $S-R$ pairings compared to switching from standard to non-standard pairings. We assume according to TEC, memory files were formed faster in the latter, which caused interference after switching the $S-R$ pairings. Finally, our study showed that current multitasking research is limited in ecological validity by focusing predominantly on dual-tasks and would benefit from research with more complex task settings beyond dual-tasks.
\end{abstract}

Keywords: dual-task, triple-task, task coordination, multitasking

\section{INTRODUCTION}

$\mathrm{M}$ Ultitasking can be found in different areas of everyday life. Its importance can be demonstrated by the example of driving a car, because you should perform several tasks simultaneously, such as navigating the car, steering, and braking, while you must be aware of changes in your environment. When you drive, you need to react to changes in the environment, such as people crossing the road, while you are making a phone call, there will be consequences. As a result, there could be longer response times, or you are no longer focused on the conversation. One of these two tasks is probably impaired or cannot be completed. Furthermore, as a driver you must constantly react to visual stimuli, like people crossing the road, or traffic lights. Commonly, you have to stop your vehicle on a red light and may continue driving on a green light. A red light is therefore linked to a different response than a green light. This means that, in everyday life, there are different types of stimuli that are coupled to different response modalities. It is questionable whether people are able to react faster and more accurately if they have to respond to certain types of stimuli with a certain type 
of reaction. Under which circumstances, however, can we talk about multitasking? Is driving a car a form of multitasking, or have several tasks merged into one big task with more than one task components or subtasks?

The term task refers to a cognitive or behavioral goal, which is given by instructions (Monsell 1996). Instructions provide a clear specification of how a task must be processed. However, people must also be willing to accept these instructions as their task. Once a task has been taken on, the instruction establishes a relationship between the stimulus given and a reaction required. An example of such a task is when someone is instructed to press a button as soon as they discover the letter "A" on a screen. Studies on multitasking use clearly defined and isolated stimuli, such as sounds or visually presented forms. This allows to manipulate the time between the presentation of the first and second stimulus on a millisecond level. Additionally, clearly defined reactions to the tasks should be used, so that response times can be measured precisely, i.e. participants understood that a certain stimulus must be reacted to by performing a certain action, e.g. pressing a button and that the pairing of stimuli and responses are fixed and thus predictable (see, Künzell et al. 2018 and; Hackman 1969 for a discussion on task definition).

A common way to investigate human multitasking with such simple tasks is the dual-task paradigm (see, e.g., Koch et al. 2018, for a review). Studies based on the dual-task paradigm investigate the performance of participants in a dual-task in relation to their performance in single-tasks (Pashler and Sutherland 1998). In a dualtask, two stimuli are to be processed simultaneously, which often results in a poorer performance compared to the processing of the same stimuli presented sequentially. This difference in performance can be reflected in longer response times or higher error rates. This performance impairment is known as dual-task cost or dual-task interference (Huestegge et al. 2014). The magnitude of this interference is supposed to depend on the extent the two tasks use the same cognitive processing structures and how complex or difficult they are (Wickens 1981, 2008). In the car example, a driver could be confronted with two rather simple tasks: traffic light turns green (task: go) or they hear a siren (task: look).
According to Wickens, both tasks can theoretically be performed equally fast at the same time (perfect timesharing) as each of the two tasks incorporate separate stimulus and response modalities. However, if two visual stimuli were to be appearing (same stimulus modality), for example, the traffic light turns green and a good friend is showing up at the right side of the pedestrian crossing, it would not be so easy to process the stimuli in perfect time-sharing and interference would occur.

Combining only two extremely simple tasks into one paradigm remains the most straightforward but also the least complex way of researching basic multitasking. In fact, in the long history of multitasking, beginning with Welford (1952), who examined the effect of the psychological refractory period with two stimuli, there were investigations into limitations of tasks (Norman and Bobrow 1975), different paradigms (Pashler 1984, 1994; Monsell 2003), modalities (Pashler 1990; Schumacher et al. 2001), automatization (Maquestiaux et al. 2018; Strobach and Schubert 2017b), processing order (Strobach et al. 2018), attention control (Hirst et al. 1980; Kramer et al. 1995), inhibition (Koch et al. 2010), long-term training effects (Liepelt et al. 2011; Strobach and Schubert 2017b; Schumacher et al. 2001; Strobach et al. 2013; Bherer et al. 2005), and transfer effects (Bherer et al. 2008; Strobach et al. 2012; Liepelt et al. 2011), but the complexity of the basic dual-task paradigm was never increased by adding a third task. However, adding a third task can grant valuable insight into how interference costs change when the complexity increases and can give a better approximation of how handling multiple concurrent tasks might be realized in complex every-day situations such as the driving example above. It is also of interest to test whether the cost of changing a dual-task into a triple-task increase in a comparable manner when changing a single-task into a dual-task.

After all, most everyday activities involve more (sub)tasks than just two. However, current research in the field of multitasking does not allow straightforward hypotheses about the effects of a third task on dual-task performance. Theories, such as the aforementioned resource theory of Wickens (1981; see also Tombu and Jolicœur 2003), or Pashler's (1984, 1990, 
1994) response selection bottleneck, are based exclusively on studies with two tasks. A framework that was not intended to explain and model triple-task effects, but which seems to be a reasonable theoretical framework to explain and model such effects, is the Theory of Event Coding (TEC) by Hommel et al. (2001; Hommel 2019). According to TEC, a single, common representation medium for perceived events and the intended reaction or action forms the core structure of the functional architecture for perception and reaction planning. The key assumption is that stimulus representations and action intentions are not differently coded so that they have to be translated into each other, rather they are part of a common code, a common representational medium. The representation of stimuli and responses can 'overlap'. If, for example, a stimulus that appears on the left side of a screen is to be responded to by pressing with the left hand, location features are shared with each other. These location-specific features are represented in so-called feature maps and could bind to an action - pushing a button - and are stored in an event file. The same holds for color-, sound- or shapefeatures. This binding between stimulus and response can be categorized as standard or non-standard pairings. Standard pairings are pairings in which a visual stimulus is responded to with a manual response, or an auditory stimulus is responded to with a vocal response. Non-standard pairings are for example visual-vocal and auditory-manual pairings. Hazeltine et al. (2006; see also Hazeltine and Ruthruff 2006) showed that the dualtask costs were more than twice as high in non-standard pairings than in standard pairings. Göthe et al. (2016) broke this down even further: They not only examined the standard pairing of stimulus and response (modality pairing) but also whether the features within a task were compatible (feature pairing), i.e. whether a location stimulus appearing on the left side of the screen must also be responded to with a left button (standard response modality and standard feature pairing). In the case of non-standard modality pairing and non-standard feature pairing the location had to be responded to with the voice. When a stimulus appeared on the right side, participants had to respond by saying "left" and when a stimulus appeared on the left side, participants had to respond by saying "right". Essentially, dual-tasks were used to induce high versus low interference conditions by using two kinds of stimulus-response (S-R) pairings (i.e. Göthe et al. 2016; Tombu and Jolicoeur 2004). The high interference condition is realized by two visual-manual (S-R) pairing tasks, the low interference condition is realized by a combination of a visual-manual and auditory-vocal task. The resulting interference is based on the fact that in the two visual-manual tasks both stimuli are presented visually and were to be responded to manually so that they share similar characteristics even if one stimulus is color and the other is location and both are standard modality pairings. This means that although standard pairings are given, there is interference in the sense of dual-task costs. According to TEC, the combination of two visual-manual tasks leads to an overlap in the bindings, which now cause interference. According to Göthe et al. (2016), interference is caused by sharing a representational medium, which is only possible if stimuli and responses are in the same domain and have the same feature dimensions.

If one now extends typical dual-tasks by adding another task, several considerations stand to reason. In general terms, it is difficult to construct three tasks that can be assigned three independent S-R-pairings. Schumacher et al. (2001) showed that after training a dualtask, which consisted of a visual-manual and an auditoryvocal task, some participants no longer showed dualtask costs. In his visual-manual task participants were instructed to decide whether a circle appeared on the left, in the middle or on the right side of the screen, and in the auditory-vocal task whether the pitch was low, medium, or high. We decided to use slightly modified tasks and to extend the dual-task of Schumacher et al. (2001) with a color discrimination task because it is comparable to location tasks (Pisella et al. 1998). Thus, the resulting triple-task was made up of two visual-manual tasks (with response modalities hand and feet) and one auditoryvocal task (with response modality voice). According to TEC, there should be increased interference between the two visual-manual tasks due to the overlap of the two $S-R$ pairings. Through the instructions given in certain S-R pairings, it was possible that you have to respond to a location stimulus with your left hand and to a certain 
color with your left foot, these two tasks (S-R pairings) shared the spatial LEFT code. In TEC, such a code provides the basis for processes as perceiving and producing events at a certain position in space. This results in an overlap of features and the response time of the task that is completed second decreases significantly (Stoet and Hommel 2002, 1999). However, we had a standard feature pairing for the visual-location task and a non-standard feature pairing for the visual-color task. Together with the increased interference, this will probably lead to a preference of the visual-location task over the visual-color task because standard feature pairings may be preferred (Göthe et al. 2016). The auditory-pitch task, in contrast, was performed without influence by the other two tasks according to TEC because its processing stream did not overlap with the visual pairing tasks.

The aim of this study was to examine the practicability of adding a third task to the common dual-task paradigm, extending it to a triple-task paradigm, and explore whether effect patterns systematically differ when three tasks are to be completed. Additionally, it should be explored whether a triple-task leads to increased response times compared to single-tasks.

\section{MetHOdS}

\section{Participants}

19 students ( 9 females and 10 males, $M=23.32$, SD $=2.60)$ took part in this experiment. All participants had normal or corrected-to-normal vision and no hearing impairments. They provided informed consent and were given course credit or $9 €$ as compensation for their participation. Due to a technical issue (the audio cable was broken), four records were lost. Thus, 15 participants were included in the final analysis.

\section{Setup}

The experiment was programmed in MatLab® 2019a with the Psychtoolbox-3.013 (Brainard et al. 2016) on a PC running Linux OS $\AA$ with Ubuntu 18.04 LTS. The study was conducted in noise-reduced medium-lit cabins.
The visual stimuli were displayed on an $\mathrm{EIZO \circledR} \mathrm{color}$ monitor with a screen diagonal of 27 inches and a frame rate of $144 \mathrm{~Hz}$ at a resolution of $3840 \times 2160$ pixels. A The BlackBox® toolkit response pad with a voice key feature was used to capture response time of the motor and the vocal responses. One visual task was completed with the index and middle finger of the dominant hand via two adjacent keys on the response pad. The other visual task was completed with both feet and the respective foot pedals. The Sennheiser® Model PC3 headset was used to record the voice and reproduce the auditory stimuli.

\section{Task}

As an extension of the basic methodology of Schumacher et al. (2001), participants performed three twochoice response time tasks: a visual-manual (color discrimination), a visual-manual (location discrimination), and an auditory-vocal (pitch discrimination) task. Each task was generally structured as follows: first, participants were presented a fixation screen for 500,1000 , or $1500 \mathrm{~ms}$ with a white square $\left(3.7^{\circ}\right.$ side length) as a fixation object in the center of the screen. The stimuli in the single-tasks were presented for $200 \mathrm{~ms}$ and the white fixation square stayed on the screen until the participant responded. In the location discrimination single-task, participants responded with their hand or feet, depending on the S-R pairing, to the location (and direction) of a white arrow $\left(1.5^{\circ}\right.$ height) appearing randomly and equally distributed at the left or right side of the fixation square by pressing a button (left arrow with the index finger or left foot and right arrow with the middle finger or right foot).In the color single-task, participants responded with their hand or feet, depending on the S-R pairing, to the color that the fixation square turned to. The color was either green (RGB: $0,255,0$ ) or turquoise (RGB: 0, 255, 255). The participant responded with a button press (green square with the index finger or left foot and turquoise square with the middle finger or right foot). In the pitch single-task, participants responded vocally via the voice key to a heard sine wave tone at frequencies of either 350 or $1650 \mathrm{~Hz}$ by saying "TIEF" or "HOCH" (German for: "LOW"/ "HIGH"). 
In the triple-task, participants had to respond to all three tasks simultaneously (tasks presented with an SOA of $0 \mathrm{~ms}$ ).

\section{Design}

Participants had to complete two conditions which we will always call "S-R pairing" (color-foot, locationhand, and pitch-voice (CF|LH|PV) and location-foot, color-hand, and pitch-voice (LF|CH|PV)) in two distinct S-R orders (order A with first S-R pairing: CF|LH|PV and order $B$ with first S-R pairing: $L F|C H| P V$, see Fig. 1). One S-R pairing condition consisted of three different uniform blocks and five mixed blocks. A uniform block comprised of 20 trials of only one type of single-task in the order location (LH or LF), color (CF or $\mathrm{CH}$ ), and pitch (PV). A mixed block consisted of the three single-task types each and the triple-task with a total of 12 singletasks and 40 triple-tasks in each block. The tasks were randomly distributed in each block. Half of the participants started with the S-R pairing CF LH|PV, in which they had to respond with their feet to the color, with their hand to the location and with their voice to the pitch, followed by the S-R pairing LF|CH|PV, in which feet and hand responded to the other visual stimulus (S-R order A). The other half of the participants started with the S-R pairing $L F|C H| P V$ and switched to S-R pairing $C F|L H| P V$ (S-R order B). The S-R pairing was switched in each session with the same S-R order.

Participants were instructed to perform all the tasks as quickly and accurately as possible. They were told not to respond in a particular order and to give equal priority to all tasks. In total, participants had to participate in three sessions on three consecutive days. Each day, they completed both S-R pairing conditions.

\section{Analyses}

Vocal responses were analyzed at the time the voice key was triggered using the R-Package "VoiceExperiment" (Tillmann 2017) in unclear cases in the analysis, trials were listened to and manually classified. RStudio 3.5 (RStudio Team 2016) was used with the tidyverse package version 1.2.1 (Wickham 2017) for data prepara-

\section{Figure 1}

Schematic representation of the design and the tasks. a. shows both possible stimulus-response ( $S$ - $R$ ) pairings. In the $S$ - $R$ pairing $C F / L H \mid P V$, participants had to respond to the color (green or turquoise) of the fixation square with their feet, the location of the arrow (left or right) with their dominant hand, and to the pitch (low or high) with their voice. In the S-R pairing $L F / C H / P V$, the participants had to respond to the color with their hand, to the location of the arrow with their feet, and the pitch with their voice. $b$. shows both $S$ - $R$ orders which also represent the between-subject factor. In $S$ - $R$ order $A$, participants first had to perform the stimulus-response pairing ( $S$ - $R$ pairing) colorfoot, location-hand, and pitch-voice (CF/LHIPV) and then location-foot, color-hand, and pitch-voice (LF/CHIPV). In the S-R order B, the S-R pairings were reversed in order. In each $S$ - $R$ pairing participants first

\section{a. S-R pairings}

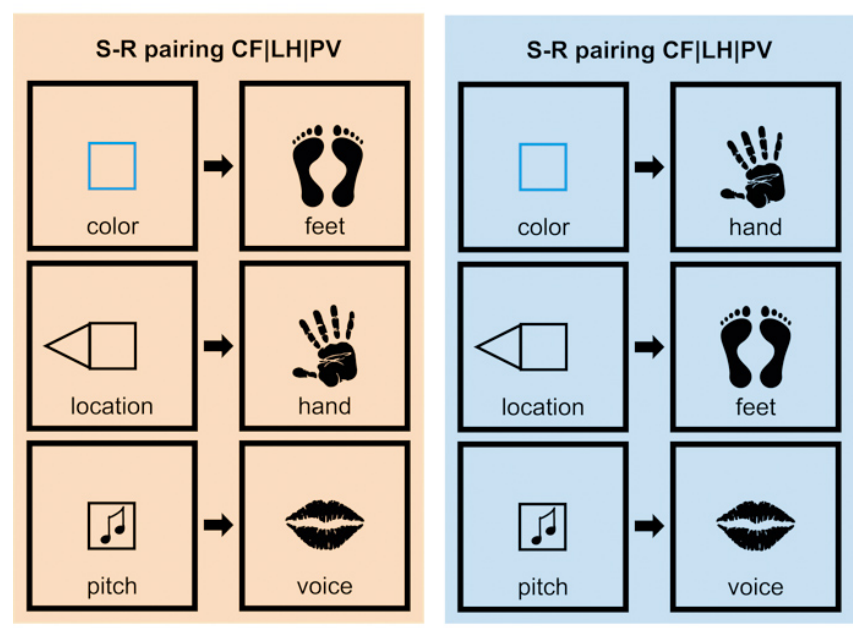

\section{b. S-R orders}

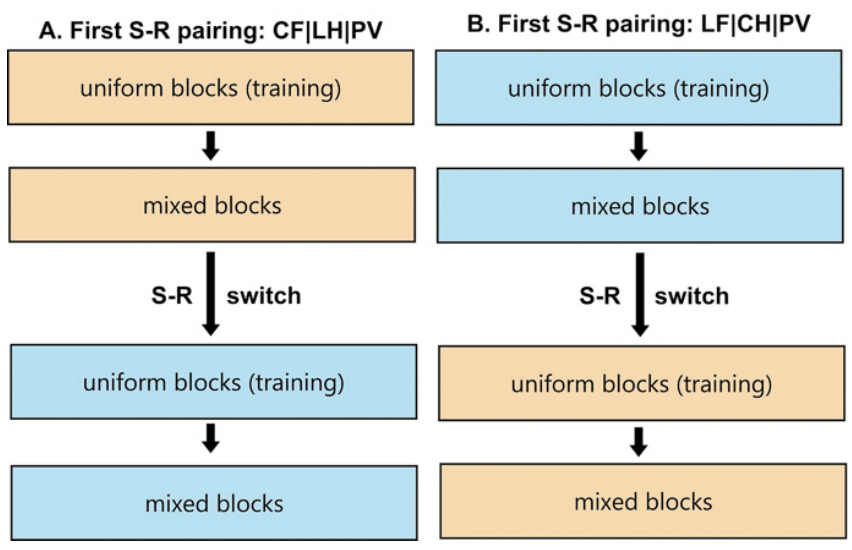


tion and creating figures and jamovi version 1.1 (jamovi project 2018) to calculate repeated measure ANOVAs and post hoc analyses. For the analyses of all effects, we included single-task and triple-task trials only from mixed blocks (uniform blocks were only used for training the S-R pairings). Only correct trials were included in the analyses. This means that in the triple-task all three tasks had to be responded correctly (error rate in single-tasks: $4.9 \%$, triple-task: $10.2 \%$ ). All trials with response times faster than $80 \mathrm{~ms}$ and slower than $4500 \mathrm{~ms}$ were removed (single-tasks: $0.9 \%$, triple-task: $2.9 \%$ ). If not stated otherwise, we calculated mean response times per participant and S-R order. Post hoc tests were conducted on the estimated marginal means with Welch's t-test and we used the Welch-Satterthwaite equation for computing degrees of freedom.

\section{RESULTS}

In the following analysis we considered the effects of single-tasks (ST) and the triple-task (TT) in mixed-blocks. Descriptive values can be found in Table 1. For the analyses, the single-tasks and the triple-task were calculated separately in repeated measures ANOVAs. The effects were examined by post hoc comparisons. Originally, we did not expect any effects between the two S-R orders $A$ with first S-R pairing: color-foot, location-hand, and pitch-voice (CF|LH|PV) and B with first S-R pairing: location-foot, color-hand, and pitch-voice (LF|CH|PV), but since there seemed to be systematical differences, we reported the results separately for the two S-R orders.

\section{Single-Tasks}

In a first step we analyzed single-tasks from mixed blocks to investigate how they are processed in the tripletask context. Single-tasks in uniform blocks (see Table 1) were not analyzed in detail. They only served as preparation for the triple-task. In general, the data is descriptively similar to Schumacher's et al. (2001) study, with two minor differences: Their participants were faster in uniform (pure) single-task blocks and fastest in visualmanual tasks (in our study: location-hand or location-foot tasks).

A repeated-measures ANOVA was calculated for single-tasks in mixed-blocks with response modality (foot, hand, vs. voice), and S-R pairing (CF|LH|PV vs. $\mathrm{LF}|\mathrm{CH}| \mathrm{PV}$ ) as a within-subject factor and S-R order (A vs. B) as a between-subject factor. The main effect for response modality, $F(2,26)=4.06, p=.029, \eta_{p}^{2}=0.238$, was significant. The main effect for $S-R$ pairing, $F(1,13)$ $=4, p=.067, \eta_{p}^{2}=0.235$, and the between subject effect, $F(1,13)=0.01, p=.924, \eta_{p}^{2}=0.001$, were not significant. The interaction of $S-R$ pairing and $S-R$ order, $F(1,13)=$ 45.73, $\mathrm{p}<.001, \eta_{p}^{2}=0.779$, response modality and $\mathrm{S}-\mathrm{R}$ pairing, $F(2,26)=35.11, p<.001, \eta_{p}^{2}=0.73$, response modality, S-R pairing and S-R order, $F(2,26)=11.19$, $\mathrm{p}<.001, \eta_{p}^{2}=0.463$, and response modality and S-R order, $F(2,26)=3.91, p=.033, \eta_{p}^{2}=0.231$, were significant. Importantly, participants responded faster in the firstly learned S-R pairing compared to the secondly learned $S-R$ pairing (later: 'S-R switching effect'). In S-R order $A$, the $S-R$ pairing $C F|L H| P V(M=830)$ was faster than the S-R pairing $L F|C H| P V(M=988 \mathrm{~ms}): M=-158 \mathrm{~ms}$, $\mathrm{t}(13)=-6.41, \mathrm{p}<.001,95 \% \mathrm{Cl}[-212 \mathrm{~ms},-105 \mathrm{~ms}]$; in S-R order $\mathrm{B}$, the $\mathrm{S}-\mathrm{R}$ pairing $\mathrm{LF}|\mathrm{CH}| \mathrm{PV}(\mathrm{M}=860)$ was faster than the S-R pairing CF|LH|PV (M = $946 \mathrm{~ms})$ : $M$ $=-86 \mathrm{~ms}, \mathrm{t}(13.0)=-3.26, \mathrm{p}=.006,95 \% \mathrm{Cl}[-143 \mathrm{~ms}$, $-29 \mathrm{~ms}])$.

Concerning the response modalities in the singletasks, it was shown that participants responded significantly faster with their hand $(\mathrm{M}=882 \mathrm{~ms})$ than with their foot $(M=953 \mathrm{~ms}), M=-71 \mathrm{~ms}, \mathrm{t}(26)=-2.46, \mathrm{p}=.021$, $95 \% \mathrm{Cl}$ [-130 ms, $-12 \mathrm{~ms}]$, and faster with their voice $(\mathrm{M}=882 \mathrm{~ms})$ than with their foot, $\mathrm{M}=-71 \mathrm{~ms}, \mathrm{t}(26)=$ $-2.47, \mathrm{p}=.02,95 \% \mathrm{Cl}[-130 \mathrm{~ms},-12 \mathrm{~ms}]$, but there was no difference between their hand and voice, $M=0 \mathrm{~ms}$, $\mathrm{t}(26)=0.01, \mathrm{p}=.99,95 \% \mathrm{Cl}[-59 \mathrm{~ms}, 60 \mathrm{~ms}]$.

As mentioned above, there was a significant S-R switching effect in the interaction S-R pairing and S$R$ order, i.e. participants responded faster in the firstly learned S-R pairing compared to the subsequent $S-R$ pairing. When comparing the firstly learned $S-R$ pairings between the two $\mathrm{S}-\mathrm{R}$ order conditions, there were no differences (order A with S-R pairing CF|LH|PV, $M=830$ ms and order B with S-R pairing LF $|\mathrm{CH}| \mathrm{PV}, \mathrm{M}=860$ $\mathrm{ms}), \mathrm{M}=-30 \mathrm{~ms}, \mathrm{t}(15.1)=-0.46, \mathrm{p}=.654,95 \% \mathrm{Cl}[-170$ 
Table 1

Response times and standard deviations in milliseconds for single-tasks (ST, from single-task blocks and mixed-task blocks) and triple-task (TT) and stimulus-response (S-R) pairings (color-foot, location-hand, and pitch-voice (CF/LHIPV) and location-foot, color-hand, and pitch-voice $(L F / C H \mid P V))$. Data are shown separately for the two S-R orders A. First S-R pairing: CF-LH-PV and B. First S-R pairing: LF-CH-PV in all three response modalities.

S-R order

\begin{tabular}{|c|c|c|c|c|c|c|c|c|c|c|c|c|c|c|c|}
\hline \multirow{4}{*}{ Task } & \multirow{4}{*}{ Block } & \multirow{4}{*}{$\begin{array}{c}\text { S-R } \\
\text { pairing }\end{array}$} & \multirow{2}{*}{\multicolumn{6}{|c|}{ A. First S-R pairing: CF-LH-PV }} & \multirow{2}{*}{\multicolumn{7}{|c|}{ B. First S-R pairing: LF-CH-PV }} \\
\hline & & & & & & & & & & & & & & & \\
\hline & & & \multicolumn{2}{|c|}{ Foot } & \multicolumn{2}{|c|}{ Hand } & \multicolumn{2}{|c|}{ Voice } & \multirow{2}{*}{$\begin{array}{c}\text { S-R } \\
\text { pairing }\end{array}$} & \multicolumn{2}{|c|}{ Foot } & \multicolumn{2}{|c|}{ Hand } & \multicolumn{2}{|c|}{ Voice } \\
\hline & & & $M$ & $S D$ & $M$ & $S D$ & $M$ & $S D$ & & $M$ & $S D$ & $M$ & $S D$ & $M$ & $S D$ \\
\hline \multirow{4}{*}{ ST } & \multirow{2}{*}{ Uniform } & $\mathrm{CF} \mid \mathrm{L}$ & 554 & 90 & 329 & 31 & 736 & 7 & $\mathrm{LF}|\mathrm{CH}| \mathrm{PV}$ & 409 & 75 & 446 & 62 & 641 & 114 \\
\hline & & $\mathrm{LF}|\mathrm{CH}| \mathrm{PV}$ & 480 & 67 & 506 & 91 & 773 & 118 & $\mathrm{CF}|\mathrm{LH}| \mathrm{PV}$ & 550 & 79 & 340 & 446 & 693 & 95 \\
\hline & \multirow{2}{*}{ Mixed } & CF|LH|PV & 943 & 168 & 626 & 79 & 920 & 160 & $\mathrm{LF}|\mathrm{CH}| \mathrm{PV}$ & 807 & 171 & 897 & 149 & 875 & 154 \\
\hline & & $\mathrm{LF}|\mathrm{CH}| \mathrm{PV}$ & 886 & 116 & 1151 & 176 & 927 & 181 & $\mathrm{CF}|\mathrm{LH}| \mathrm{PV}$ & 1176 & 236 & 856 & 126 & 805 & 114 \\
\hline \multirow{2}{*}{ TT } & \multirow{2}{*}{ Mixed } & CF|LH|PV & 1133 & 204 & 1129 & 256 & 1626 & 324 & $\mathrm{LF}|\mathrm{CH}| \mathrm{PV}$ & 1168 & 244 & 1167 & 247 & 1370 & 281 \\
\hline & & $\mathrm{LF}|\mathrm{CH}| \mathrm{PV}$ & 1242 & 239 & 1397 & 254 & 1895 & 380 & CF|LH|PV & 1253 & 266 & 1190 & 163 & 1434 & 274 \\
\hline
\end{tabular}

Figure 2

Median response times (calculated from individual participant's means) for single-tasks (mixed blocks) from $S-R$ order $A$ or $B$ as a function of stimulus (location, color, and pitch) and response modality (foot, hand, and voice). The black arrow symbolizes the direction of the modality switch from pre- to post-switch. Colored boxes mark the 25th to 75 th percentile range of the group data, dots show the individual participant's mean RTs

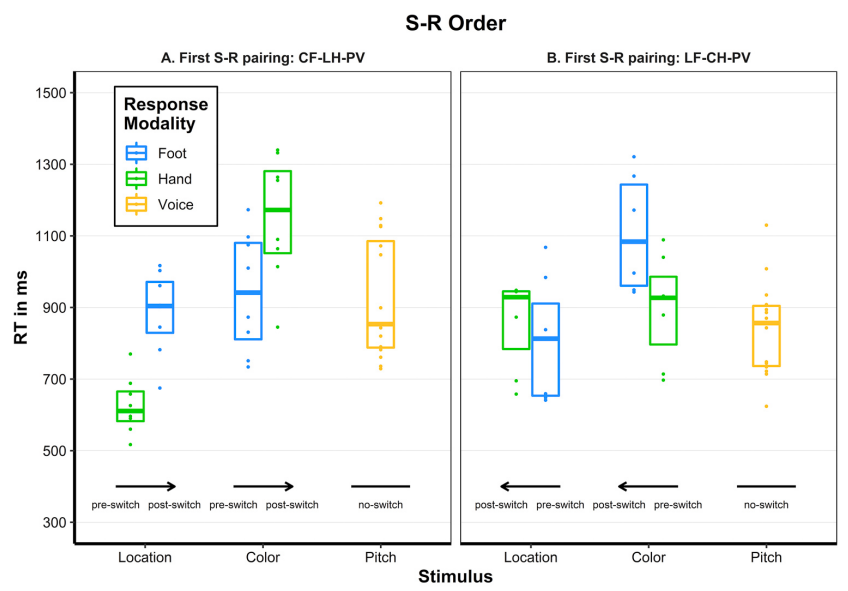

$\mathrm{ms}, 110 \mathrm{~ms}$ ]. Also when comparing the subsequently learned $S-R$ pairings (after the switch) there were no differences either (A with S-R pairing - LF $|\mathrm{CH}| \mathrm{PV}, \mathrm{M}=$ $988 \mathrm{~ms}$ and $B$ with $\mathrm{CF}|\mathrm{LH}| \mathrm{PV}, \mathrm{M}=946 \mathrm{~ms}), \mathrm{M}=42 \mathrm{~ms}$, $\mathrm{t}(15.1)=0.64, \mathrm{p}=.529,95 \% \mathrm{Cl}[-97 \mathrm{~ms}, 182 \mathrm{~ms}]$. In the interaction S-R pairing and response modality we observed a small stimuli-effect. In particular, in S-R pairing $C F|L H| P V$ the location stimulus $(L)$ was responded to first in respect of time followed by the pitch stimulus (P) but in the S-R pairing LF $|\mathrm{CH}| \mathrm{PV}$ both stimuli ( $\mathrm{L}$ vs. $P)$ were responded to equally fast. The response to the color stimulus ( $\mathrm{CF}$ or $\mathrm{CH}$ ) was always the slowest regardless of the S-R pairing. To be more precise, in S$\mathrm{R}$ pairing $\mathrm{CF}|\mathrm{LH}| \mathrm{PV}$, participants responded faster with their hand to the location task, $(\mathrm{LH}, \mathrm{M}=741 \mathrm{~ms})$ than with their voice to the pitch task ( $P V, M=863 \mathrm{~ms}$ ), $M=$ $-122 \mathrm{~ms}, \mathrm{t}(52)=-2.95, \mathrm{p}=.005,95 \% \mathrm{Cl}[-205 \mathrm{~ms},-39$ $\mathrm{ms}]$ ) and faster than with their foot to the color task (CF, $M=1060 \mathrm{~ms}), M=-319 \mathrm{~ms}, \mathrm{t}(52)=-7.72, p<.001,95 \%$ $\mathrm{Cl}$ [-402 ms, -236 ms], and pitch-voice was significantly faster than color-foot (CF, $\mathrm{M}=-197 \mathrm{~ms}), \mathrm{t}(52)=-4.77$, $\mathrm{p}<.001,95 \% \mathrm{Cl}[-280 \mathrm{~ms},-114 \mathrm{~ms}]$. In S-R pairing $\mathrm{LF}|\mathrm{CH}| \mathrm{PV}$, participants responded in the location-foot pairing ( $L F, M=847 \mathrm{~ms}$ ) as fast as in the pitch-voice pairing ( $P V, M=901 \mathrm{~ms}$ ), $M=-54 \mathrm{~ms}, \mathrm{t}(52)=-1.31, \mathrm{p}$ $=.195,95 \% \mathrm{Cl}[-137 \mathrm{~ms}, 29 \mathrm{~ms}]$, but in the location- 
foot pairing significantly faster than in the color-hand pairing $(\mathrm{CH}, \mathrm{M}=1024 \mathrm{~ms}), \mathrm{M}=-177 \mathrm{~ms}, \mathrm{t}(52)=-4.29$, $\mathrm{p}<.001,95 \% \mathrm{Cl}$ [-260 ms, $-94 \mathrm{~ms}]$. In the pitch-voice (PV) pairing, they responded significantly faster than in the color-hand pairing $(\mathrm{CH}), \mathrm{M}=-123 \mathrm{~ms}, \mathrm{t}(52)=-2.97$, $\mathrm{p}=.004,95 \% \mathrm{Cl}[-206 \mathrm{~ms},-40 \mathrm{~ms}]$.

Furthermore, participants responded faster with their hand to the location stimulus ( $\mathrm{LH}$ in $\mathrm{S}-\mathrm{R}$ pairing CF|LH|PV) than with their foot (LF in S-R pairing $\mathrm{LF}|\mathrm{CH}| \mathrm{PV}), \mathrm{M}=-177 \mathrm{~ms}, \mathrm{t}(52)=-4.29, \mathrm{p}<.001,95 \% \mathrm{Cl}$ [-260 ms, -94 ms]. No difference was evident in the response to the color stimulus between the two response modalities foot (CF in S-R pairing $\mathrm{CF}|\mathrm{LH}| \mathrm{PV}$ ) and hand ( $\mathrm{CH}$ in S-R pairing $\mathrm{LF}|\mathrm{CH}| \mathrm{PV}), \mathrm{M}=36 \mathrm{~ms}, \mathrm{t}(55.2)=0.94$, $\mathrm{p}=.351,95 \% \mathrm{Cl}[-41 \mathrm{~ms}, 112 \mathrm{~ms}]$.

The main finding in the interaction of response modality, S-R pairing, and S-R order was, as already mentioned, in response to the location stimulus. Participants responded significantly faster with their hand (LH in S-R pairing $C F|L H| P V)$ in S-R order $A$ than with their foot (LF in $S-R$ pairing $L F|C H| P V)$ in $S-R$ order $B$. In this case, both response modalities were the firstly learned $S-R$ pairing in the respective S-R order. All other comparisons between the S-R orders showed no significance.

\section{Triple-Task}

To investigate whether response behavior differs systematically in the triple-task compared to dual-tasks, we analyzed the response times of the triple-task (see Table 1). Since we were the first to investigate triple-tasks and the complex interactions are potentially unforeseeable, the following analyses can be regarded exploratory rather than strictly hypothesis-driven.

To investigate response times in the whole experimental design, a repeated-measure ANOVA was calculated for the triple-task with the within-subject factor response modality (foot, hand, vs. voice), and S-R pairing (CF|LH|PV vs. $\mathrm{LF}|\mathrm{CH}| \mathrm{PV})$ and the between-subject factor S-R order (A vs. B). The main effects for response modality, $F(2,26)=20.29, p<.001, \eta_{p}^{2}=0.609$, and $S$ $\mathrm{R}$ pairing, $\mathrm{F}(1,13)=7.44, \mathrm{p}=.017, \eta_{p}^{2}=0.364$, were significant, but the main effect for $\mathrm{S}-\mathrm{R}$ order was not significant, $F(1,13)=1.74, p=.21, \eta_{p}^{2}=0.118$. The interactions response modality and S-R order, $F(2,26)$ $=4.25, \mathrm{p}=.025, \eta_{p}^{2}=0.246$, and $\mathrm{S}-\mathrm{R}$ pairing and $\mathrm{S}-\mathrm{R}$ order, $F(1,13)=22.19, p<.001, \eta_{p}^{2}=0.631$, were significant. The interactions response modality and $S-R$ pairing, $F(2,26)=2.3, p=.121, \eta_{p}^{2}=0.15$, and response modality, $S-R$ pairing and $S-R$ order, $F(2,26)=0.86, p=$ $.435, \eta_{p}^{2}=0.062$, were not significant.

Regarding the response modalities main effects, post hoc t-tests showed that participants responded significantly faster with their foot $(M=1204 \mathrm{~ms})$ than with their voice $(M=1586 \mathrm{~ms}), M=-382 \mathrm{~ms}, \mathrm{t}(26)=-5.67$, $\mathrm{p}<.001,95 \% \mathrm{Cl}$ [-521 ms, -244 ms], and significantly faster with their hand than with their voice, $M=-360$ $\mathrm{ms}, \mathrm{t}(26)=-5.35, \mathrm{p}<.001,95 \% \mathrm{Cl}[-499 \mathrm{~ms},-222 \mathrm{~ms}]$. They further responded similarly fast with their foot (M $=1204 \mathrm{~ms})$ and with their hand $(\mathrm{M}=1225 \mathrm{~ms}), \mathrm{M}=$ $-22 \mathrm{~ms}, \mathrm{t}(26)=-0.32, \mathrm{p}=.749,95 \% \mathrm{Cl}[-160 \mathrm{~ms}, 117$ $\mathrm{ms}]$. Additionally, for the S-R pairing main effect, the participants responded significantly faster in $S-R$ pairing $\mathrm{CF}|\mathrm{LH}| \mathrm{PV}(\mathrm{M}=1299 \mathrm{~ms})$ than in S-R pairing LF $|\mathrm{CH}| \mathrm{PV}$ $(M=1378), M=-79 \mathrm{~ms}, \mathrm{t}(13)=-2.73, \mathrm{p}=.017,95 \% \mathrm{Cl}$ [-141 ms, $-17 \mathrm{~ms}]$.

In the interaction of $\mathrm{S}-\mathrm{R}$ pairing and $\mathrm{S}-\mathrm{R}$ order there was also a S-R switching effect: in S-R order A, participants were significantly faster in S-R pairing $C F|L H| P V$ $(\mathrm{M}=1300 \mathrm{~ms})$ than S-R pairing $\mathrm{LF}|\mathrm{CH}| \mathrm{PV}(\mathrm{M}=1516$ $m s), M=-215 \mathrm{~ms}, \mathrm{t}(13)=-5.44, \mathrm{p}<.001,95 \% \mathrm{Cl}[-301$ $\mathrm{ms},-130 \mathrm{~ms}]$. In S-R order B, however, only a numerical difference was found between the S-R pairing $L F|C H| P V$ $(\mathrm{M}=1240 \mathrm{~ms})$ and the S- $R$ pairing CF|LH|PV ( $\mathrm{M}=1297$ $\mathrm{ms}), \mathrm{M}=57 \mathrm{~ms}, \mathrm{t}(13)=1.36, \mathrm{p}=.198,95 \% \mathrm{Cl}[-34 \mathrm{~ms}$, $149 \mathrm{~ms}$.

An unexpected effect was observed in the interaction of response modality and S-R order. Participants showed no difference between the response modalities hand and foot within and between the S-R orders, but the response modality voice was slowest in both $S-R$ orders compared to the second slowest response time in each triple-task. In S-R order A this meant that participants responded significantly slower with their voice ( $\mathrm{M}=1765 \mathrm{~ms})$ than with their hand, $(\mathrm{M}=1268 \mathrm{~ms}), \mathrm{M}$ $=497 \mathrm{~ms}, \mathrm{t}(26)=5.4, \mathrm{p}<.001,95 \% \mathrm{Cl}[308 \mathrm{~ms}, 687$ $\mathrm{ms}]$, but in S-R order $\mathrm{B}$, they responded not significantly slower with their response modality voice $(M=1407 \mathrm{~ms})$ 
than with their foot, $(M=1215 \mathrm{~ms}), M=192 \mathrm{~ms}, \mathrm{t}(26)$ $=1.95, \mathrm{p}=.062,95 \% \mathrm{Cl}[-11 \mathrm{~ms}, 394 \mathrm{~ms}]$. There was also an unexpected significant difference between the $S-R$ orders $A$ and $B$ in response modality voice, $M=358$ $\mathrm{ms}, \mathrm{t}(26.8)=2.72, \mathrm{p}=.011,95 \% \mathrm{Cl}[88 \mathrm{~ms}, 628 \mathrm{~ms}]$.

Figure 3

Median response times for the triple-task (calculated from individual participant's means) from $S-R$ order $A$ (left panel) and $S$ - $R$ order $B$ (right panel) as a function of Stimulus (Location, Color, and Pitch) and Modality (Foot, Hand, and Voice). The black arrow symbolizes the direction of the modality change from pre- to post-switch. Colored boxes mark the 25th to 75th percentile range of the group data, dots show the individual participant's mean RTs.

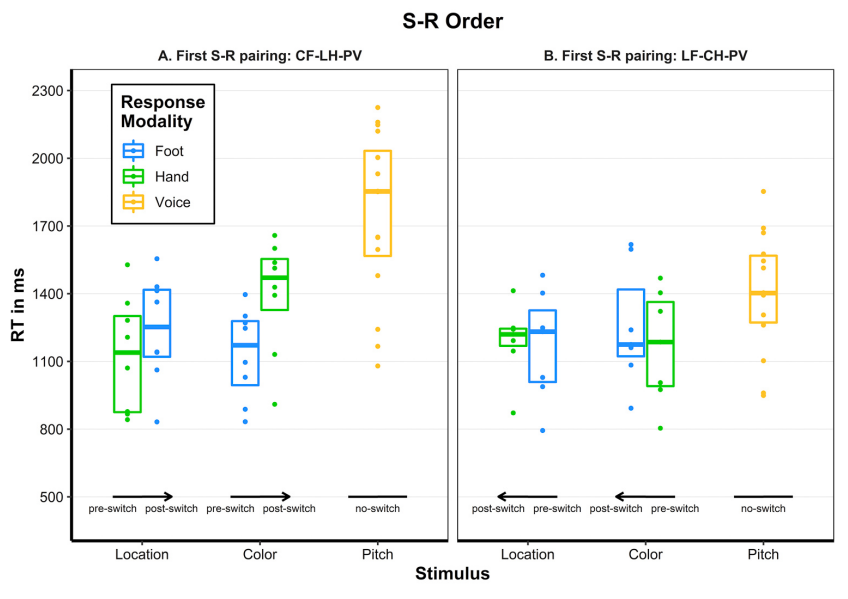

\section{Triple-Task-Costs}

In the third and last step, we analyzed triple-task costs. These were calculated for each condition from the difference between single-tasks and the triple-task (see Table 2). A repeated-measures ANOVA was calculated for mean differences with response modality (foot, hand, or voice), and S-R pairing (CF|LH|PV vs. LF|CH|PV) as within-subject factors and S-R order (A vs. B) as a between-subject factor. The main effect for response modality, $\mathrm{F}(2,26)=34.35, \mathrm{p}<.001, \eta_{p}^{2}=0.725$, was significant. The main effect for S-R pairing, $F(1,13)=2.74$, $p=.122, \eta_{p}^{2}=0.174$, as well as the between-subject effect S-R order, $\mathrm{F}(1,13)=3.93, \mathrm{p}=.069, \eta_{p}^{2}=0.232$, were not significant.

The interactions response modality and $S-R$ pairing, $\mathrm{F}(2,26)=21.31, \mathrm{p}<.001, \eta_{p}^{2}=0.621$, and response modality, S-R pairing and S-R order, $F(2,26)=14.54$, $p<.001, \eta_{p}^{2}=0.528$, were significant. The interactions S-R pairing and S-R order, $\mathrm{F}(1,13)=0.3, \mathrm{p}=.594, \eta_{p}^{2}=$ 0.022 , and response modality and $S-R$ order, $F(2,26)=$ 2.23, $\mathrm{p}=.128, \eta_{p}^{2}=0.146$, were not significant.

In the main effect of response modality, participants showed the lowest cost in response modality foot ( $M$ $=250 \mathrm{~ms}$ ), followed by the costs in response modality hand $(\mathrm{M}=343 \mathrm{~ms})$ and voice $(\mathrm{M}=704 \mathrm{~ms})$. However, the difference between the costs in response modalities hand and foot were not significant, $\mathrm{M}=-93 \mathrm{~ms}, \mathrm{t}(26)=$ $-1.6, \mathrm{p}=.121,95 \% \mathrm{Cl}[-211 \mathrm{~ms}, 26 \mathrm{~ms}]$. The difference between the costs in response modalities hand and voice, $\mathrm{M}=-361 \mathrm{~ms}, \mathrm{t}(26)=-6.24, \mathrm{p}<.001,95 \% \mathrm{Cl}[-$ $480 \mathrm{~ms},-242 \mathrm{~ms}]$, as well as the difference between response modalities foot and voice, $M=-453 \mathrm{~ms}, \mathrm{t}(26)$ $=-7.84, \mathrm{p}<.001,95 \% \mathrm{Cl}[-572 \mathrm{~ms},-335 \mathrm{~ms}]$, were significant.

Furthermore, there was a significant interaction of response modality and $S-R$ pairing. In $S-R$ pairing CF|LH|PV, participants showed an almost linear increase in costs from color-foot (CF, $M=138 \mathrm{~ms}$ ) via location-hand ( $\mathrm{LH}, \mathrm{M}=423 \mathrm{~ms}$ ) to pitch-voice (PV, M = $672 \mathrm{~ms}$ ). With significant differences between color-foot and location-hand, $\mathrm{M}=-286 \mathrm{~ms}, \mathrm{t}(38.8)=-4.4, \mathrm{p}<.001$, $95 \% \mathrm{Cl}$ [-418 ms, $-153 \mathrm{~ms}$ ], as well as location-hand and pitch-voice, $\mathrm{M}=-248 \mathrm{~ms}, \mathrm{t}(38.8)=-3.82, \mathrm{p}<.001,95$ $\% \mathrm{Cl}$ [-381 ms, -115 ms]. In S-R pairing LF|CH|PV, however, we observed that participants showed increasing costs from color-hand ( $\mathrm{CH}, \mathrm{M}=262 \mathrm{~ms}$ ) via location-foot (LF, M = $363 \mathrm{~ms}$ ) to pitch-voice (PV, $\mathrm{M}=736 \mathrm{~ms}$ ). The difference between the costs in color-hand and locationfoot was not significant, $M=100 \mathrm{~ms}, \mathrm{t}(38.8)=1.55, \mathrm{p}=$ $.13,95 \% \mathrm{Cl}$ [-32 ms, $233 \mathrm{~ms}$ ] but between location-foot and pitch-voice, $\mathrm{M}=-373 \mathrm{~ms}, \mathrm{t}(38.8)=-5.74, \mathrm{p}<.001$, $95 \% \mathrm{Cl}$ [-506 ms, $-240 \mathrm{~ms}]$. Taken together, at least descriptively the S-R pairing with the color stimulus caused the lowest costs (in S-R pairing CF|LH|PV with color-foot and in S-R pairing LF|CH|PV with color-hand).

In the three-way interaction of response modality, S-R pairing, and S-R order we report only one effect. The reason for this was that the costs did not differ between S-R orders and S-R pairings for the response modalities hand ( $\mathrm{LH}$ and $\mathrm{CH}$ ) and foot (LF and CF) (the interactions 
Table 2

Triple-task costs and standard deviations in milliseconds as a function of stimulus-response (S-R) pairings (color-foot, location-hand, and pitch-voice (CF/LH/PV) and location-foot, color-hand, and pitch-voice $(L F / C H / P V))$ and response modality (foot, hand, and voice). Triple-task costs were calculated from single-task - triple-task. Data are shown separately for the two S-R orders A. First S-R pairing: CF-LH-PV and $B$. First S-R pairing: $L F-C H-P V$.

\begin{tabular}{|c|c|c|c|c|c|c|c|c|c|c|c|c|c|}
\hline \multirow{4}{*}{$\begin{array}{c}\text { S-R } \\
\text { pairing }\end{array}$} & \multicolumn{13}{|c|}{ S-R order } \\
\hline & \multicolumn{6}{|c|}{ A. First S-R pairing: CF-LH-PV } & \multicolumn{7}{|c|}{ B. First S-R pairing: LF-CH-PV } \\
\hline & \multicolumn{2}{|c|}{ Foot } & \multicolumn{2}{|c|}{ Hand } & \multicolumn{2}{|c|}{ Voice } & \multirow[t]{2}{*}{$\begin{array}{c}\text { S-R } \\
\text { pairing }\end{array}$} & \multicolumn{2}{|c|}{ Foot } & \multicolumn{2}{|c|}{ Hand } & \multicolumn{2}{|c|}{ Voice } \\
\hline & $M$ & $S D$ & $M$ & $S D$ & $M$ & $S D$ & & $M$ & $S D$ & $M$ & $S D$ & $M$ & $S D$ \\
\hline CF $|\mathrm{LH}| \mathrm{PV}$ & 190 & 177 & 504 & 220 & 705 & 208 & $\mathrm{LF}|\mathrm{CH}| \mathrm{PV}$ & 361 & 153 & 270 & 192 & 495 & 235 \\
\hline $\mathrm{LF}|\mathrm{CH}| \mathrm{PV}$ & 356 & 161 & 246 & 133 & 967 & 282 & CF $|\mathrm{LH}| \mathrm{PV}$ & 77 & 234 & 334 & 126 & 629 & 232 \\
\hline
\end{tabular}

response modality and S-R order, as well as S-R pairing and $\mathrm{S}-\mathrm{R}$ order, were not significant). In the three-way interaction, only in the $S-R$ order $A$ in the S-R pairing $\mathrm{LF}|\mathrm{CH}| \mathrm{PV}$ the response modality voice $(\mathrm{V})$ showed an outlier upwards ( $\mathrm{M}=967 \mathrm{~ms}$ ), as can be seen in Table 2 . The costs were for participants almost twice as high as under the same conditions in the S-R order $B$ in the S-R pairing $\mathrm{LF}|\mathrm{CH}| \mathrm{PV}(\mathrm{M}=500 \mathrm{~ms}), \mathrm{M}=472 \mathrm{~ms}, \mathrm{t}(48.2)=$ 4.53, p<.001, $95 \% \mathrm{Cl}$ [262 ms, $683 \mathrm{~ms}$ ], explaining the significant interaction.

\section{DISCUSSION}

In the past, multitasking research was dominated by different dual-task paradigms. Although dual-tasks allow for a significant amount of variability like simultaneous processing, sequential processing or task-switching, the variability of complex everyday situations that change often in unpredicted ways can be much more larger. The aim of this study was to examine the effects of three simultaneous tasks, allowing us to quantify the progression of multitasking costs. The present study showed that the response times in the triple-task were up to two times higher than dual-tasks in comparable dual-task studies (Schumacher et al. 2001; Tombu and Jolicoeur 2004; Maquestiaux et al. 2018; Strobach and Schubert 2017b). It was further observed that participants responded fastest to the visual tasks in almost all cases. Among the two visual tasks, standard feature pairings were preferred over the non-standard feature pairings (location over color). The auditory task in the triple-task showed the slowest response times. Another unexpected and interesting effect was found in the differential switching costs between the two S-R pairings. Remember that participants had to switch their response modality to the visual stimuli. Participants who started with S-R pairing CF|LH|PV (S-R order A) showed two times higher response times across all response modalities after the switch. Participants who began with S-R pairing $\mathrm{CH}|\mathrm{LF}| \mathrm{PV}$ (S-R order B) showed no switching costs.

\section{A Comparison between Single-Task, Dual-Task, and Triple-Task}

Due to the introduction of a new task, the triple task, it was important for us to be comparable to Schumacher et al. (2001), who introduced one of the most well-known dual tasks and to which we oriented ourselves. We were able to establish this comparability. The descriptive comparison of single-tasks of the uniform blocks and those of Schumacher et al. (2001), which were also processed in pure single-task blocks (homogeneous single-tasks in experiments 1 and 3) showed high similarity in response times. The fact that the response times in mixed blocks increased in comparison to the uniform blocks also fitted 
into our considerations. In mixed blocks, which had a larger number of possible tasks (three single-tasks and one triple-task), working memory load and therefore response times increased (see section "Mobilized Effort" Tombu and Jolicoeur 2004).

A closer look at the response modalities showed that in single-tasks the two response modalities hand and voice were equally fast, and the response modality foot was the slowest. In the triple-task, however, the response modalities hand and foot were equally fast, and the response modality voice was the slowest. In singletasks, the data supported previous research results. Hazeltine and Ruthruff (2006) found that non-standard feature pairings resulted in longer response times than standard feature pairings (see also Göthe et al. 2016). The results from Tanaka and Shimojo (1996) supported this effect. In their experiment, color discrimination took more time than discrimination of location when participants used the same response modalities. However, response times in the triple-task differ in respect of standard vs. non-standard feature pairings. Participants showed the highest response times for the response modality voice, despite the fact that pairing pitch and voice is considered standard feature pairing. One possible explanation is that participants worked the tripletask strategically different by giving the two visual tasks priority to process them simultaneously. This may be indicative of a proceduralization strategy to reduce coordination complexity. Which contradicts Logan and Gordon (2001), who have shown that participants prefer to perform dual-tasks sequentially rather than in parallel to avoid binding problems.

Participants also showed different effects in the response modalities in single-tasks and the triple-task for standard feature pairings with respect to the S-R pairings (CF|LH|PV or LF|CH|PV). In particular, in single-tasks, participants responded faster to the location or pitch stimulus (stimuli effect) than to the color stimulus. With respect to the S-R pairings, this response time pattern was not observed in the triple-task. In both S-R pairings, both visual tasks were given priority. Descriptively, it was observed that participants always responded fastest to the location stimulus, but the difference between location and color stimulus (LH vs. CF or LF vs. CH) was not significant. We, therefore, assume that some kind of task grouping occurred, despite our instructions to not give priority to any of the tasks. Gaining additional insight through comparison with other research is difficult because this distinct combination of responding to two visual stimuli simultaneously with the response modalities hand and foot was not employed before. Only Moeller et al. (2015) used both modalities in a dual-task prime-probe design but participants performed the two tasks one after the other. Thus, they could not serve as a comparison for simultaneous occurrences of both S-R combinations. However, an indication of the changed prioritization or grouping of visual tasks could be found in studies on coordination skills. Liepelt et al. (2011; Strobach et al. 2015) compared training simultaneous dual-tasks and training single-tasks and a superior effect from training the dual-task in contrast to training the two single-tasks separately. This benefit may be due to the necessity that the combination of two tasks to a dual-task affords extra coordination in order to treat the two tasks as one task. If this reasoning makes sense it holds also for the triple-task with the difference that three single-tasks have now to be treated as one task. This affords more coordination in comparison to dual-tasks and participants have to optimize coordination. One strategy is to pack effector procedures together to one procedure that is paired with the same type of stimulus. In the case of the triple-task this the pairing of the visual stimuli with those motor effectors that are intended to change the state of an object like the button and the pedal. In their review, Strobach and Schubert (2017a) discussed similar mechanisms in the training of dualtasks, which support our assumptions. If few resources are available and the participants are given the freedom to decide which task should be prioritized, they could optimally train their attention allocation and task coordination. As a result, a high level of efficiency is achieved in the retrieval of task rules and coordination.

An insight into the coordination of the triple-task could also be seen in the differences to dual-tasks. In the dualtasks of Schumacher et al. (2001), the time between the response to the first and second task was $390 \mathrm{~ms}$ (373 $\mathrm{ms}$ to $400 \mathrm{~ms}$ ). For the triple-task, in the present study, there were only $53 \mathrm{~ms}$ (30 ms to $76 \mathrm{~ms}$, depending on 
the S-R pairing) between the first task and second task responses. This was the case with the triple-task even though participants almost always completed the location stimulus first and the color stimulus second (both visual tasks!). The response time difference between the second visual task and the third task, the auditory task, was $344 \mathrm{~ms}$ (337 ms and $351 \mathrm{~ms}$, depending on the S-R pairing). Thus, the response time difference between the slowest visual task and the auditory task was comparable to Schumacher et al.. Additionally, in the triple-task participants nearly almost processed the auditory task at last. Thus, a significant difference in the processing of dual-tasks and triple-tasks became apparent. The response time difference between the first and second tasks was much shorter, but the response time difference to the first task was longer. A possible explanation for this is that a different strategy of processing is applied in the triple-task than in the dual-task. Participants first processed both visual stimuli and coordinated them before they responded by trying to integrate the two visual tasks into one. With respect to proposed explanations of dual-task processing, one can assume that task-relevant features in the two visual tasks of the triple-task overlap are integrated and processed sequentially (Koch 2009; Navon and Miller 1987). Only if dual-task consists of non-overlapping S-R pairings, seemingly parallel processing should be possible (Logan and Gordon 2001). Since response times between the two visual tasks in the triple-task were not significantly different, it is reasonable to assume that there was no overlap. If the subtask-wise integration and coordination is a general strategy, a training study with the triple-task should render further evidence.

Generally, we found significantly higher response times for the triple-task (S-R Pairing CF|LH|PV: CF 1197 ms, LH 1164 ms, PV 1534 ms; S-R pairing LF|CH|PV: LF $1210 \mathrm{~ms}, \mathrm{CH} 1286 \mathrm{~ms}$, PV $1637 \mathrm{~ms}$ ) than to singletasks and dual-tasks in Schumacher's experiments (in their experiment 1 , response times in dual-tasks were $725 \mathrm{~ms}$ for the auditory-vocal tasks and were $352 \mathrm{~ms}$ for the visual-manual tasks; in their experiment 3 , response times for dual-tasks with the non-standard feature pairing for the visual-manual tasks were $778 \mathrm{~ms}$ and were $1178 \mathrm{~ms}$ for the standard feature pairing auditory-vocal tasks). In the triple-task, a larger number of operations had to be prepared and retained in the working memory (three stimuli each with two features and three response modalities could be combined in many different ways). The increased requirements caused the response times to rise (see section "Mobilized Effort" Tombu and Jolicoeur 2004). The fact that the triple-task cannot easily be compared with other dual-tasks is also evident in the comparison of Experiment 3 run by Schumacher et al. (2001). Although the response times increased significantly due to the use of non-standard feature pairings, they still did not reach similar response times as in the triple-task. This was especially evident when comparing the standard feature pairings in the triple-task, which were performed fastest, and the non-standard feature pairings in experiment 3 run by Schumacher et al. (2001).

Another effect that specific to the triple-task was a difference of $79 \mathrm{~ms}$ between the S-R pairings CF|LH|PV and LF|CH|PV (regardless of the response modalities and S-R orders). In single-tasks, no significant difference was observed. The reason for this, however, could maybe be identified if we look more closely at the S-R pairings in the different $S-R$ orders ( $A$ or $B$ ). While the first $S-R$ pairing to be processed in each $S-R$ order was responded faster than the second $S-R$ pairing (S-R pairing switching effect) in single-tasks, the same pattern was seen in the triple-task only in S-R order A. In S-R order $\mathrm{B}$ no difference could be observed in switching from S-R pairing CH|LF|PV to $L F|C H| P V$. In general, we expected that no S-R pairing switching costs would be observed or that they would only be seen in the first tasks after switching (Monsell 2003). However, it seems that the participants found it easier to start with S-R pairing $L F|C H| P V$ and then switch to S-R pairing CF $|L H| P V$. There was no difference between S-R pairing CF|LH|PV in S-R order A vs. B. One assumption that could explain the effect would be that coordinating the triple-task was easier if the hand had a standard feature pairing, while coordination was more difficult if the hand had a nonstandard feature pairing. This would explain, at least in part, why the switch of S-R pairings did not affect S-R order $\mathrm{B}$, but a significant effect in S-R order $\mathrm{A}$. 


\section{Triple-Task-Costs}

A major objective of this study was exploring the progression of triple-task costs. Costs of multitasking are predominantly studied in the context of dual-tasks by comparing the single-task with the dual-task (Schumacher et al. 2001; Tombu and Jolicoeur 2004). The analog comparison proved to be very difficult for the triple-task. At the outset of Schumacher's et al. experiment 1 , all tasks had standard modality and feature pairings, the dual-task costs were $14 \mathrm{~ms}$ for the visualmanual task and $70 \mathrm{~ms}$ for the auditory-vocal task. However, in their experiment 3 for standard modality and non-standard feature pairings, the costs were higher (visual-manual with non-standard feature pairing 187 ms, auditory-vocal with standard feature pairing 357 $\mathrm{ms}$ ). Comparing dual-task costs of Schumacher et al. to triple-task costs in the present study, for the S-R pairing $\mathrm{CF}|\mathrm{LH}| \mathrm{PV}$ independent of the S-R order (LH with standard feature pairing $423 \mathrm{~ms}$, CF with non-standard feature pairing $138 \mathrm{~ms}$ and $\mathrm{PV}$ with standard feature pairing $672 \mathrm{~ms}$ ), dual-task costs from Schumacher et al. were much lower. However, in S-R pairing CF|LH|PV was an almost linear increase in costs from foot over hand to voice. Furthermore, it was also shown that the lowest costs were not for the hand, which has standard feature pairing, but for the modality foot with non-standard feature pairing. A similar result was observed with the S-R pairing $L F|C H| P V$ independent of the S-R order, (CH 262 ms, LF 363 ms, and PV 736 ms). More interestingly, the non-standard feature pairings in triple-task showed similar costs as non-standard feature pairings in dual-tasks. However, it should be considered that the non-standard feature pairings in single-tasks were responded to slowest and grouped in the triple-task with standard feature pairings. Furthermore, it should be considered that due to increased complexity, a comparison of single-tasks with the triple-task is problematic because the single-tasks lose their independence due to the necessity to coordinate them which is done within a different task set. Even if the calculation was done with single-tasks from mixed blocks only (which were slower than single-tasks in uniform blocks), single-tasks are still processed much faster than the triple-task.
It remains to be discussed whether triple-task costs can be calculated in the same way as dual-task costs. One possibility would be to add any possible combination of dual-tasks to the triple-task. With the help of these, a comparison of single-tasks to dual-tasks and of the latter to triple-tasks would be possible. This would also contribute to a better understanding of how the subtasks in dual- and triple-tasks become interactively coordinated. However, it would make the experiment much more complex for the participants and lengthy in general.

\section{The Triple-Task in the Context of Different Models}

One of the most widespread structural models of dualtask processing assumes a response selection bottleneck (RSB) (Pashler 1994, 1990, 1984). The RSB can process only one task per time frame and is presumed to be located in the central system. The model assumes that only at the peripheral stages (perception and motor execution), two tasks could run at the same time. Applied to the triple-task, a clear sequence of responses to the subtasks should now have become apparent as a result of the central bottleneck. But we could not observe this, even for both visual tasks. The two visual tasks were responded to almost simultaneously. However, this observation is not an argument against the RSB. For performing a dual-task Ruthruff et al. (2001) instructed participants explicitly to respond to both stimuli simultaneously. They could detect massive interference. Participants needed much longer to respond to both tasks than for the single-tasks. They regarded this as clear evidence for the RSB. This would also explain why the response times of the triple-task were so high compared to single-tasks. However, the response modality and stimulus effects speak against the RSB model assumptions. According to the RSB model response times should be independent of the S-R pairing, i.e. after a change of the $S-R$ pairings, comparable response times should occur. This is the case for the single-tasks but not for the triple-task in S-R order A.

Resource models provide also explanations for interferences with dual-tasks. The advantage of these 
models is that they assume the ability to divide flexibly resources (whatever resources are). A single-task can be processed with $100 \%$, but two or more tasks must share the resource. When processing several tasks at the same time, $100 \%$ is now divided by the number of tasks (Norman and Bobrow 1975). On this basis, Tombu and Jolicœur (2003) developed the central capacity-sharing model (CCS). Now, dual-tasks could theoretically run at the same speed as single-tasks. CSS would now explain why the response time for the tripletask increase so much, but it also does not provide clear assumptions about the response modalities, S-R pairing switching effects, or the reason why subtasks are coordinated differentially in dual-, triple- or what seems to be generalizable in multi-tasks. One possibility to explain the observations in the triple-task is offered by TEC.

According to TEC (Hommel et al. 2001) S-R pairings are represented in a common representational medium for perceived events and the intended forms of reaction or action. In the triple-task each S-R pairing $(\mathrm{CH}, \mathrm{LH}$, CF, LF, and PV) according to TEC would be stored in so-called event files. If participants are presented an arrow pointing to the left (location task), they could request the corresponding reaction from the event file depending on instructions. Hommel (2019) extended his theory and distinguished between online files, which only exist during an activity, and memory files, which are stored in long-term storage. Transferred to our tripletask we assume that during the experiment online files were created which were adapted according to the instructions. As already discussed, the S-R pairings in the two visual tasks must have overlapped and led to strong interference. However, the feature overlapping according to Stoet and Hommel $(1999,2002)$ only led to a strongly increased response time of the second task and not of both tasks. Here we would like to take up the extension of Göthe et al. (2016) which we would like to extend as well. Göthe et al. (2016) assumed that stimuli and responses in the same domain share a representational medium. In this case, not several event files but common or linked event files should be created. These would allow participants to respond quickly and efficiently to the visual tasks in the tripletask. However, we are also aware that previous studies have concluded that when features overlapped, such as the hand and foot response modalities (both had to distinguish between left and right keys), the responses were sequential rather than parallel (Logan and Gordon 2001).

According to TEC one can hypothesize that during S$R$ pairing $C F|L H| P V$ or $L F|C H| P V$ online event files were created for the corresponding S-R pairings which should change relatively quickly after the switching of S-R pairings (Monsell 2003). However, it did not. It seemed that the pre-switch S-R pairings were converted to memory event files and that they interfered with the creating of new event files for the post-switch pairings. This was most evident in $\mathrm{S}-\mathrm{R}$ order $\mathrm{A}$, in which the change from $\mathrm{S}$ $R$ pairing $C F|L H| P V$ to $L F|C H| P V$ was performed. In S-R order $\mathrm{B}$ this observation was not evident. We suspect that the combination of location and hand (S-R) was easier and therefore possibly memory files were formed more quickly, which in turn led to greater problems when changing the S-R pairings. For location and foot (S-R), however, it seems that memory files were not created as quickly and thus have caused less or no interference.

\section{Conclusion}

Response behavior in triple-tasks cannot be easily extrapolated from single- and dual-tasks. In the tripletask, the response times increased exponentially, and the coordination of responses differs: In classical dualtasks, the first response is indicated similarly fast as compared to single-tasks and only the second response is delayed. In a triple-task setting, all three responses are delayed. Additionally, in the triple-task the theoretical importance of standard and non-standard feature pairings was not apparent per se. Both visual tasks (both standard and non-standard feature S-R pairings) in triple-task were processed and responded to nearly simultaneously. Most often the auditory task (standard feature pairing) was processed after the visual tasks and thus given the least priority. Furthermore, the grouped coordination of visual tasks in the triple-task had an enormous impact on the triple-task costs in that the non-standard feature pairing resulted in the lowest cost. Standard feature pairings had the highest costs (espe- 
cially the auditory task). Due to the completely different behavior, it was difficult to integrate the results into already existing - especially dual-task - models (like RSB, resource theories, or TEC). Finally, our study showed that multitasking research is clearly limited by the restriction to only two tasks and these results should not be generalized to everyday multitasking such as our example of driving a car. Multitasking research would benefit from an extended focus on complex situations involving more than two tasks.

\section{References}

Bherer, L., Kramer, A. F., Peterson, M. S., Colcombe, S., Erickson, K., \& Becic, E. (2005). Training effects on dual-task performance: are there age-related differences in plasticity of attentional control? Psychology and aging, 20, 695-709. https://doi.org/10.1037/08827974.20.4.695.

Bherer, L., Kramer, A. F., Peterson, M. S., Colcombe, S., Erickson, K., \& Becic, E. (2008). Transfer effects in task-set cost and dual-task cost after dual-task training in older and younger adults: further evidence for cognitive plasticity in attentional control in late adulthood. Experimental aging research, 34, 188-219. https://doi.org/10.1080/03610730802070068.

Brainard, D., Kleiner, M., \& Diederick, C. (2016). Psychtoolbox-3.

Göthe, K., Oberauer, K., \& Kliegl, R. (2016). Eliminating dual-task costs by minimizing crosstalk between tasks: The role of modality and feature pairings. Cognition, 150, 92-108. https://doi.org/10.1016/j.cognition.2016.02.003.

Hackman, J. R. (1969). Toward understanding the role of tasks in behavioral research. Acta psychologica, 31, 97-128. https://doi.org/10.1016/0001-6918(69)90073-0.

Hazeltine, E., \& Ruthruff, E. (2006). Modality pairing effects and the response selection bottleneck. Psychological research, 70, 504-513. https://doi.org/10.1007/s00426-005-0017-3.

Hazeltine, E., Ruthruff, E., \& Remington, R. W. (2006). The role of input and output modality pairings in dualtask performance: evidence for content-dependent central interference. Cognitive psychology, 52, 291-345. https://doi.org/10.1016/j.cogpsych.2005.11.001.

Hirst, W., Spelke, E. S., Reaves, C. C., Caharack, G., \& Neisser, U. (1980). Dividing Attention Without Alternation or Automaticity. Journal of experimental psychology: General, 1, 98-117. https://doi.org/10.1037/00963445.109.1.98.

Hommel, B. (2019). Theory of Event Coding (TEC) V2.0: Representing and controlling perception and action. Attention, Perception, \& Psychophysics, 81, 2139-2154. https://doi.org/10.3758/s13414-019-017794.

Hommel, B., Müsseler, J., Aschersleben, G., \& Prinz, W. (2001). The Theory of Event Coding (TEC): a framework for perception and action planning. The Behavioral and brain sciences, 24, 849-78; discussion 878-937. https://doi.org/10.1017/s0140525x01000103.

Huestegge, L., Pieczykolan, A., \& Koch, I. (2014). Talking while looking: on the encapsulation of output system representations. Cognitive psychology, 73, 72-91. https://doi.org/10.1016/j.cogpsych.2014.06.001.

jamovi project. (2018). jamovi (Version 1.0).

Koch, I. (2009). The role of crosstalk in dual-task performance: evidence from manipulating responsecode overlap. Psychological research, 73, 417-424. https://doi.org/10.1007/s00426-008-0152-8.

Koch, I., Gade, M., Schuch, S., \& Philipp, A. M. (2010). The role of inhibition in task switching: a review. Psychonomic Bulletin \& Review, 17, 1-14. https://doi.org/10.3758/PBR.17.1.1.

Koch, I., Poljac, E., Müller, H., \& Kiesel, A. (2018). Cognitive structure, flexibility, and plasticity in human multitasking-An integrative review of dual-task and task-switching research. Psychological Bulletin, 144, 557-583. https://doi.org/10.1037/bul0000144.

Kramer, A. F., Larish, J. F., \& Strayer, D. L. (1995). Training for Attentional Control in Dual Task Settings: A Comparison of Young and Old Adults. Journal of Experimental Psychology: Applied, 1, 50-76. https://doi.org/10.1037/1076-898X.1.1.50.

Künzell, S., Broeker, L., Dignath, D., Ewolds, H., Raab, M., \& Thomaschke, R. (2018). What is a task? An ideomotor perspective. Psychological research, 82, 4-11. https://doi.org/10.1007/s00426-017-0942-y.

Liepelt, R., Strobach, T., Frensch, P., \& Schu- 
bert, T. (2011). Improved intertask coordination after extensive dual-task practice. Quarterly journal of experimental psychology (2006), 64, 1251-1272. https://doi.org/10.1080/17470218.2010.543284.

Logan, G. D., \& Gordon, R. D. (2001). Executive control of visual attention in dual-task situations. Psychological Review, 108, 393-434. https://doi.org/10.1037//0033295X.108.2.393.

Maquestiaux, F., Ruthruff, E., Defer, A., \& Ibrahime, S. (2018). Dual-task automatization: The key role of sensory-motor modality compatibility. Attention, perception \& psychophysics, 80, 752-772. https://doi.org/10.3758/s13414-017-1469-4.

Moeller, B., Hommel, B., \& Frings, C. (2015). From hands to feet: Abstract response representations in distractor-response bindings. Acta psychologica, 159, 69-75. https://doi.org/10.1016/j.actpsy.2015.05.012.

Monsell, S. (1996). Unsolved mysteries of the mind. In V. Bruce (Ed.), Unsoved Mysteries of the Mind: Tutorial Essays in Cognition (pp. 93-148). Hove: Erblaum (UK) Taylor\&Francis.

Monsell, S. (2003). Task switching. Trends in Cognitive Sciences, 7, 134-140. https://doi.org/10.1016/S1364-6613(03)00028-7.

Navon, D., \& Miller, J. (1987). Role of outcome conflict in dual-task interference. Journal of experimental psychology. Human perception and performance, 13, 435-448. https://doi.org/10.1037/0096-1523.13.3.435.

Norman, D. A., \& Bobrow, D. G. (1975). On datalimited and resource-limited processes. Cognitive psychology, 7, 44-64. https://doi.org/10.1016/00100285(75)90004-3.

Pashler, H. (1984). Processing stages in overlapping tasks: Evidence for a central bottleneck. Journal of Experimental Psychology: Human Perception and Performance, 10, 358-377. https://doi.org/10.1037//00961523.10.3.358.

Pashler, H. (1990). Do response modality effects support multiprocessor models of divided attention? Journal of Experimental Psychology: Human Perception and Performance, 16, 826-842. https://doi.org/10.1037//00961523.16.4.826.

Pashler, H. (1994). Dual-task interference in simple tasks: Data and theory. Psychological Bul- letin, 116, 220-244. https://doi.org/10.1037//00332909.116.2.220.

Pashler, H., \& Sutherland, S. (1998). The psychology of attention (Vol. 15): Cambridge, MA: MIT press. Pisella, L., Arzi, M., \& Rossetti, Y. (1998). The timing of color and location processing in the motor context. Experimental brain research, 121, 270-276. https://doi.org/10.1007/s002210050460.

RStudio Team. (2016). RStudio: Integrated Development Environment for R. Boston, MA: RStudio, Inc. Ruthruff, E., Pashler, H., \& Klaassen, A. (2001). Processing bottlenecks in dual-task performance: Structural limitation or strategic postponement? Psychonomic Bulletin \& Review, 8, 73-80. https://doi.org/10.3758/BF03196141.

Schumacher, E. H., Seymour, T. L., Glass, J. M., Fencsik, D. E., Lauber, E. J., Kieras, D. E., et al. (2001). Virtually Perfect Time Sharing in Dual-Task Performance: Uncorking the Central Cognitive Bottleneck. PSYCHOLOGICAL SCIENCE, 12, 101-108. https://doi.org/10.1111/1467-9280.00318. Stoet, G., \& Hommel, B. (1999). Action Planning and the Temporal Binding of Response Codes. Journal of experimental psychology. Human perception and performance, 25, 1625-1640. https://doi.org/10.1037/00961523.25.6.1625.

Stoet, G., \& Hommel, B. (2002). Feature integration between perception and action. In W. Prinz \& B. Hommel (Eds.), Common mechanisms in perception and action: Attention and Performance, Vol. XIX (pp. 538-552). Oxford: Oxford University Press.

Strobach, T., Frensch, P., Müller, H., \& Schubert, T. (2015). Evidence for the acquisition of dual-task coordination skills in older adults. Acta psychologica, 160, 104-116. https://doi.org/10.1016/j.actpsy.2015.07.006.

Strobach, T., Frensch, P. A., Soutschek, A., \& Schubert, T. (2012). Investigation on the improvement and transfer of dual-task coordination skills. Psychological research, 76, 794-811. https://doi.org/10.1007/s00426011-0381-0.

Strobach, T., Hendrich, E., Kübler, S., Müller, H., \& Schubert, T. (2018). Processing order in dualtask situations: The "first-come, first-served" principle and the impact of task order instructions. At- 
tention, perception \& psychophysics, 80, 1785-1803. https://doi.org/10.3758/s13414-018-1541-8.

Strobach, T., Liepelt, R., Pashler, H., Frensch, P. A., \& Schubert, T. (2013). Effects of extensive dual-task practice on processing stages in simultaneous choice tasks. Attention, perception \& psychophysics, 75, 900-920. https://doi.org/10.3758/s13414-013-0451-z.

Strobach, T., \& Schubert, T. (2017a). Mechanisms of Practice-Related Reductions of Dual-Task Interference with Simple Tasks: Data and Theory. Advances in cognitive psychology, 13, 28-41. https://doi.org/10.5709/acp0204-7.

Strobach, T., \& Schubert, T. (2017b). No evidence for task automatization after dual-task training in younger and older adults. Psychology and aging, 32, 28-41. https://doi.org/10.1037/pag0000144.

Tanaka, Y., \& Shimojo, S. (1996). Location vs Feature: Reaction Time Reveals Dissociation Between Two Visual Functions. Vision research, 36, 2125-2140. https://doi.org/10.1016/0042-6989(95)00272-3.

Tillmann, N. (2017). VoiceExperiment: This package allows the analysis of vocal responses to psychological experiments. R package version 1.0.2. Tombu, M., \& Jolicœur, P. (2003). A central capacity sharing model of dual-task performance. Journal of Experimental Psychology: Human Perception and Performance, 29, 3-18. https://doi.org/10.1037/0096-1523.29.1.3.

Tombu, M., \& Jolicoeur, P. (2004). Virtually no evidence for virtually perfect time-sharing. Journal of experimental psychology. Human perception and performance, 30, 795-810. https://doi.org/10.1037/00961523.30.5.795.

Welford, A. T. (1952). The Psychological refractory period and the timing of high-speed performance - a review and a theory, 43(1), 2. Wickens, C. D. (1981). Processing Resources In Attention, Dual Task Performance, and Workload Assessment (Technical Report EPL-SI-3/ONR81-3). https://apps.dtic.mil/dtic/tr/fulltext/u2/a102719.pdf. Accessed 30 April 2019.

Wickens, C. D. (2008). Multiple resources and mental workload. Human factors, 50, 449-455. https://doi.org/10.1518/001872008X288394. Wickham, H. (2017). tidyverse: Easily Install and Load the 'Tidyverse'. https://CRAN.R-project.org/package=tidyverse. 